\title{
Metal@Silica Yolk-Shell Nanostructures as Versatile Bifunctional Nanocatalysts
}

\author{
Ji Chan Park and Hyunjoon Song ( $ه)$ \\ Department of Chemistry, Korea Advanced Institute of Science and Technology (KAIST), Daejeon 305-701, Republic of Korea \\ Received: 4 August 2010 / Revised: 24 August 2010 / Accepted: 31 August 2010 \\ (C) The Author(s) 2010. This article is published with open access at Springerlink.com
}

\begin{abstract}
Recent developments in nanochemistry offer precise morphology control of nanomaterials, which has significant impacts in the field of heterogeneous catalysis. Rational design of bifunctional catalysts can influence various aspects of catalytic properties. In this review, a new class of bifunctional catalysts with a metal@silica yolk-shell nanostructure is introduced. This structure has many advantages as a heterogeneous catalyst since it ensures a homogeneous environment around each metal core, and particle sintering is effectively eliminated during high temperature reactions. The catalysts exhibit high activity and recyclability in gas- and solution-phase reactions. It is anticipated that appropriate selection of bifunctional components and optimal structural control will significantly further enhance the catalytic properties, and enable target reaction-oriented development of new catalysts.
\end{abstract}

\section{KEYWORDS}

Yolk-shell nanostructure, nanocatalyst, bifunctionality, metal nanoparticles, heterogeneous catalytic reactions

\section{Introduction}

Currently, most heterogeneous catalytic systems use bifunctional structures for enhancement of catalytic performances in various reactions [1,2]. A bifunctional catalyst is defined as a catalyst structure comprising both active metal nanoparticles and a high surface area support [3]. In a traditional view, the metal nanoparticles behave as the actual catalytically active surface where the reaction occurs, and the support stabilizes the active nanoparticles and prevents leaching or severe particle agglomeration. But recent studies of heterogeneous catalysts have explored possible roles of the support as another active component. The support can transport reactants onto the catalytic surface, control diffusion rates of the reactants and the products, and provide protons or electrons to modify total reactivity. In some cases, the support reacts with the metal nanoparticles on their interface and generates active components which actually carry out the reaction $[4,5]$. Therefore, the term, "bifunctional", is appropriate since it expresses the fact that both the metal nanoparticles and the support independently carry out multiple functions during catalytic reactions.

Since nanotechnology became a major topic of research, numerous synthetic processes have been developed in order to adjust the size, shape, and surface structure of nanoscopic objects. Morphology control of metal nanoparticles has been widely studied in various ways [6, 7]. On the other hand, the synthesis of mesoporous materials has rapidly evolved by developing ways of controlling three-dimensional

Address correspondence to hsong@ $@$ kaist.ac.kr 
arrangements of "vacancies", which can afford metal oxide materials with high surface area and regular porosity [8]. These mesoporous metal oxides are regarded as excellent support materials for the active metal nanoparticles in heterogeneous catalysts. To generate a uniform dispersion of the metal nanoparticles on the metal oxide matrix, the incipient wetness method-in which metal precursors are adsorbed on the pores and reduced by thermal and chemical treatments-has been developed and commonly used $[9,10]$. This simple process is suitable for large-scale synthesis approaching industrial use with a variety of metal components, and it has already been used in many heterogeneous reactions. However, some fundamental limits exist in this process: diffusion rates of the reactants and the products are significantly reduced for the particles that are deeply buried in the support matrix. Moreover, the morphology and size distribution of the metal nanoparticles are very difficult to uniformly control inside the pore channels, although the average diameter of the particles can be adjusted within a limited range by altering the average pore size of the support.

In order to tailor the morphology of both the active nanoparticles and the high surface area support, a couple of rational approaches have been developed. In the first method, the active nanoparticles and the mesoporous support are independently prepared, and mixed mechanically to yield a bifunctional hybrid structure [11]. This method, so-called "capillary inclusion", using a simple process involving low-power sonication, has proven to be surprisingly successful and versatile. The second method is "nanoparticle encapsulation", where a mixture of structurally welldefined metal nanoparticles and a silica precursor forms a silica network under hydrothermal conditions [12]. The resulting silica matrix contains the metal nanoparticles within it. In both cases, the active metal nanoparticles show well-controlled morphology with narrow size distributions and, after calcination, catalyze reactions with high activity.

Although these methods can tune morphology of the active nanoparticles as well as the high surface area support, problems such as irregular diffusion rates and reaction heterogeneity on the catalysts have not yet been overcome. In addition, most catalytic processes in the petroleum and chemical industries are normally performed at high temperatures above $573 \mathrm{~K}$, and under these conditions, the tiny metal nanoparticles in the catalysts tend to sinter which leads to a significant loss in catalytic activity. Even inside the silica matrix, surface melting of the particles at high temperature leads to their migration on the surface and agglomeration with neighboring particles to yield large clusters with lower surface area. In order to resolve these fundamental problems, a new concept in catalyst design is required.

If each nanoparticle has a homogeneous environment that includes the support and vacancies, the reaction behavior on each catalyst particle should be nearly identical. Current synthetic techniques in nanochemistry can provide high structural uniformity of the nanostructure at a single particle level [6]. Based on this idea, a yolk-shell nanoparticle structure was designed for a new type bifunctional catalyst as depicted in Fig. 1. The term "yolk-shell" is derived from an egg, which contains an egg yolk and white inside an outer solid shell. In spherical nanoparticles, the yolk-shell structure has a void between the core and the shell forming a hierarchical "core-void-shell" arrangement, which corresponds to the "yolk-whiteshell" arrangement in an egg [13]. It is also known as a "nanorattle", because the core is mobile when the structure is filled with a solvent [14], but nowadays most researchers use the "yolk-shell" terminology since it facilitates comparison with core-shell nanoparticles. When the metal core is surrounded by a silica shell with a sufficient void, the yolk-shell nanostructure can be regarded as a bifunctional catalyst that contains both metal and silica (or metal@silica).

Such a metal@silica yolk-shell nanostructure has many advantages for heterogeneous catalytic reactions for the following reasons.

(i) The catalytic reaction occurs on the surface of active metal nanoparticles located at the center. The size, shape, and surface structure of the metal particles can be precisely tuned by various synthetic techniques before coating with silica.

(ii) The reactants, products, and solvents can penetrate through the pores of the silica shells. The diffusion rates are controllable by adjusting pore density and average pore size of the silica shells. 


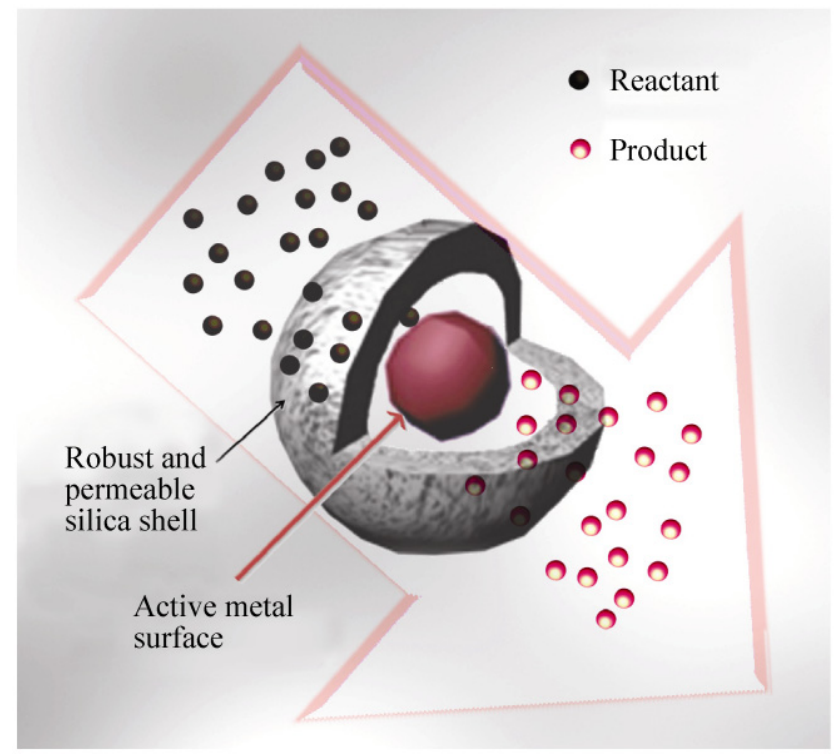

Figure 1 Metal@silica yolk-shell nanostructure as a bifunctional heterogeneous catalyst

(iii) All reactions are carried out in the void inside the shell. In other words, the yolk-shell structure acts as a "nanoreactor framework", which contains sufficient space and catalytically active surface within its structure. Each of the active nanoparticles experiences a homogeneous environment in a void surrounded by the silica shell.

(iv) In comparison with core-shell nanoparticles, the yolk-shell structure uses the entire metal core surface, not being covered with the silica shell. But strong interactions between the metal core and the shell are maintained through physical or chemical contacts in the structure.

Numerous methods for the synthesis of yolk-shell nanoparticles (or nanorattles) have been developed [15-17]; however, studies of their practical application in heterogeneous catalysis have rarely been reported. Yin et al. studied the formation of metal oxide hollow nanoparticles using the Kirkendall effect, and employed it to synthesize Pt@CoO yolk-shell nanoparticles [13]. This structure was used in gas phase reactions such as ethylene hydrogenation, and showed some catalytic activity. Joo et al. recently reported that $\mathrm{Pt}$ nanoparticles coated with mesoporous silica $\left(\mathrm{Pt} @ \mathrm{~m}-\mathrm{SiO}_{2}\right)$ exhibited remarkable stability in high temperature reactions [18]. $\mathrm{Au} @ \mathrm{ZrO}_{2}$ nanoparticles have also been tested in high temperature CO oxidation reactions $[19,20]$, and rhodium nanoparticles encapsulated by porous carbon have been employed for hydrogenation of aromatic compounds [21]. Because of the many advantages of these core-shell and yolk-shell structures, many researchers are now involved in the study of such bifunctional nanocatalysts.

In this review, we focus on the synthesis, transformation, and catalytic properties of metal@silica yolk-shell nanostructures. Silica is commonly used as a support material in bifunctional catalytic systems, because of its structural robustness and strong interaction with metal nanoparticles. We have prepared $\mathrm{Au} @ \mathrm{SiO}_{2}$ model catalysts as proof-of-concept of the yolk-shell nanocatalysts. The $\mathrm{Au} @ \mathrm{SiO}_{2}$ structure can be chemically tailored to enhance catalytic activities. The $\mathrm{Ni}_{\mathrm{SiO}}$ yolk-shell nanostructure has also been synthesized and employed for high temperature steam reforming of methane. In addition, $\mathrm{Ni@SiO}$ nanocatalysts with tiny metal cores showed high reactivity in solution-phase organic reactions. Under hydrothermal conditions, the tiny nickel cores reacted with silica to give a nickel phyllosilicate phase, which led to an interesting transformation into a new bifunctional structure. Chemical conversion and the resulting changes in reactivity of the nanocatalysts indicate that rational catalyst design is critical if catalytic performance is to be optimized.

\section{Proof-of-concept: $\mathrm{Au} @ \mathrm{SiO}_{2}$ yolk-shell nanoparticles as a model catalytic system}

The basic concept of a "nanoreactor" was introduced for Pt@CoO nanoparticles, but the CoO shell is not a support that is useful for many reactions [13]. If $\mathrm{CoO}$ can be substituted by common metal oxide supports such as silica, titania, and zirconia, the resulting metal@metal oxide structures would be suitable for many gas- and solution-phase reactions. Silica is the first choice among shell materials, because it is a wellknown support and readily forms a uniform coating on the metal surface. Gold is our choice of metal core, due to its controllable size with a narrow size distribution and high stability against harsh reaction conditions. Moreover, the chemical nature of gold is quite distinct from that of silica, which makes it possible to selectively modify only one component in gold/silica hybrid materials. For instance, thiols can

\section{Springer}


exclusively functionalize the gold surface without reacting with the silica. Using gold and silica as components, we have developed bifunctional $\mathrm{Au} @ \mathrm{SiO}_{2}$ yolk-shell nanostructures as a model catalyst, and examined their properties in order to clarify the usefulness of this structure for heterogeneous catalytic systems. $\mathrm{Au} @ \mathrm{SiO}_{2}$ core-shell and yolk-shell nanoparticles have not previously been used as nanocatalysts for heterogeneous reactions, although their structures have been reported in the literature [22]. We have shown that the materials catalyzed the reduction of $p$-nitrophenol with pseudo-first order kinetics, and the reaction rate could be increased by an order of magnitude by appropriate chemical modifications. These results confirm that such a yolk-shell nanostructure is excellent as a versatile nanoreactor framework for heterogeneous catalytic reactions.

\subsection{Synthesis of $\mathrm{Au} @ \mathrm{SiO}_{2}$ yolk-shell nanostructure with variable core sizes}

Hollow nanostructures are expected to be useful in many applications because of their high surface area and ability to store and deliver materials, and numerous synthetic protocols for hollow structures have been developed thus far [23, 24]. The yolk-shell nanoparticles have two parts - the metal cores and the shell layers-and thus the syntheses involve the formation of hollow shells in the presence of the metal cores [25]. Synthetic methods for yolk-shell nanoparticles can be divided into two types, manipulation of the core and manipulation of the shell. In the case of $\mathrm{Au} @ \mathrm{SiO}_{2}$ we used selective etching of the metal cores in metal@silica core-shell nanoparticles [26]. This method has the advantages of being a simple procedure and has wide applicability, because most metal cores are soluble in weak acids.

Gold nanoparticles were synthesized by a wellknown polyol process in the presence of polyvinylpyrrolidone (PVP) in refluxing 1,5-pentanediol [27]. The resulting spherical particles were coated with silica shells by means of the Stöber method in 2-propanol [28], yielding $\mathrm{Au} @ \mathrm{SiO}_{2}$ core-shell nanoparticles as shown in Fig. 2(b). The silica shells are evenly coated on the spherical cores with an average core size of $120 \mathrm{~nm} \pm 10 \mathrm{~nm}$ and shell thickness of $32 \mathrm{~nm} \pm 2 \mathrm{~nm}$.
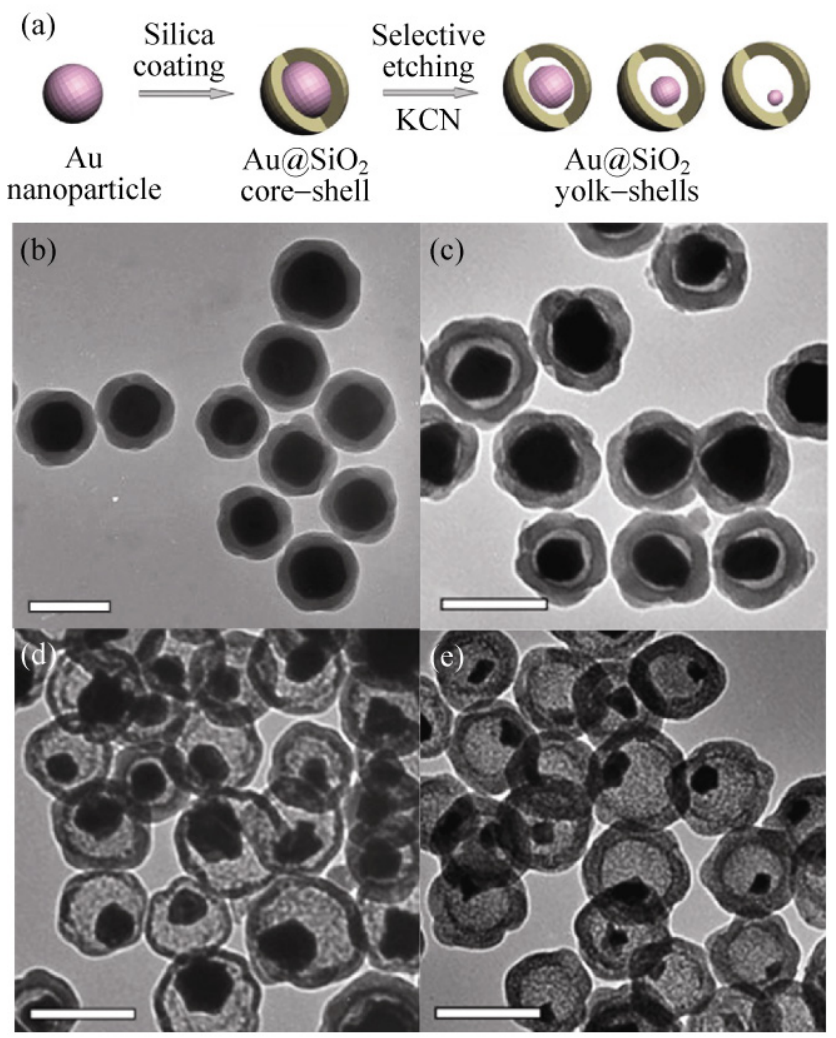

Figure 2 (a) Synthetic scheme for the $\mathrm{Au} @ \mathrm{SiO}_{2}$ yolk-shell framework; (b) TEM images of $\mathrm{Au} @ \mathrm{SiO}_{2}$ core-shell and (c)-(e) $\mathrm{Au} @ \mathrm{SiO}_{2}$ yolk-shell nanoparticles; Gold core diameters are (b) $120 \mathrm{~nm}$, (c) $104 \mathrm{~nm}$, (d) $67 \mathrm{~nm}$, and (e) $43 \mathrm{~nm}$; All scale bars represent $200 \mathrm{~nm}$. Reproduced with permission from Ref. [26]. Copyright Wiley VCH, 2008

The gold cores were selectively etched by treatment with $\mathrm{KCN}$, as shown in Eq. (1) [22], without damaging the silica shells.

$$
4 \mathrm{Au}+8 \mathrm{CN}^{-}+\mathrm{O}_{2}+4 \mathrm{H}^{+} \longrightarrow 4 \mathrm{Au}(\mathrm{CN})_{2}^{-}+2 \mathrm{H}_{2} \mathrm{O}
$$

By repeating the KCN treatment, the average size of the gold cores could be reduced to $104 \pm 9$ (Fig. 2(c)), $67 \pm 8$ (Fig. 2(d)), and $43 \mathrm{~nm} \pm 7 \mathrm{~nm}$ (Fig. 2(e)). As the gold core size decreased, the core surface became rougher with sharp edges and facets, owing to irregular etching on the different surface faces.

In order to confirm the permeability of the silica shells, diffusion rates through the silica were measured using the surface plasmon resonance peak of the gold cores. The peak maximum in the UV-vis extinction spectrum was monitored for the $\mathrm{Au} @ \mathrm{SiO}_{2}$ yolk-shell particles in 2-propanol (refractive index $(n)=1.377$ ). 
When a small amount of quinoline with high refractive index $(n=1.62)$ was added to the particle dispersion, the original peak maximum at $594 \mathrm{~nm}$ gradually shifted to $600 \mathrm{~nm}$ and saturated at that wavelength in 30 min (Fig. 3(a)). In contrast, the extinction peak of the $\mathrm{Au} @ \mathrm{SiO}_{2}$ core-shell particles did not shift at all under the same conditions. The diffusion coefficient through the silica shell can be calculated from the extinction shift using Eq. (2)

$$
D=\left(\pi R^{2} / 36\right) \times\left(V_{\mathrm{f}}^{2} / t\right)
$$

where $D$ is the diffusion coefficient, $R$ is the radius of the silica hollow shell $(82 \mathrm{~nm})$, and $V_{\mathrm{f}}$ is the volume fraction of 2-propanol in the solvent mixture. The diffusion coefficient, $D$, was estimated to be $4.74 \times$ $10^{-19} \mathrm{~m}^{2} / \mathrm{s}$, which is comparable to the value of $\sim 4.76 \times$ $10^{-19} \mathrm{~m}^{2} / \mathrm{s}$ reported for the polymer shell in Au@poly

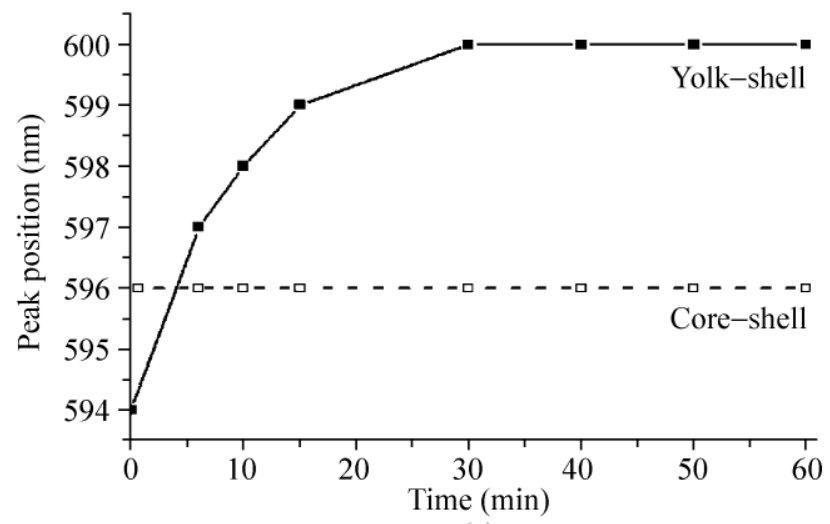

(a)

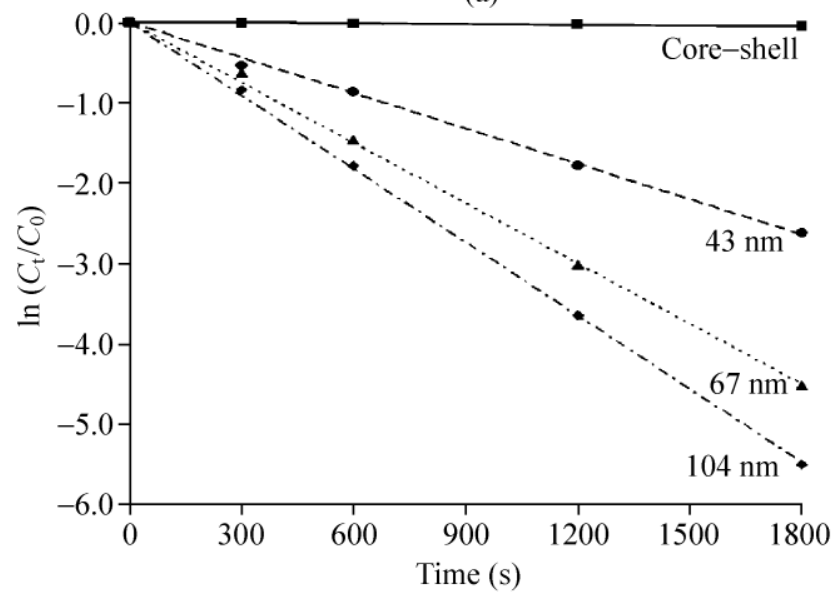

(b)

Figure 3 (a) Changes in UV-vis extinction spectra of $\mathrm{Au} @ \mathrm{SiO}_{2}$ colloidal dispersions in 2-propanol on adding quinoline; (b) Plot of $\ln \left(C_{\mathrm{t}} / C_{0}\right)$ versus time for each yolk-shell framework. Reproduced with permission from Ref. [26]. Copyright Wiley VCH, 2008 (benzyl methacrylate) yolk-shell nanoparticles [15]. This diffusion may result from the presence of defects or less polymerized sites in the amorphous silica. It indicates that the reactants, products, and solvents can move through the silica layers during the reaction, and fully access the active metal core surface.

\subsection{Study of $\mathrm{Au} @ \mathrm{SiO}_{2}$ yolk-shell nanocatalysts in $p$-nitrophenol reduction}

To demonstrate the "nanoreactor" concept, the $\mathrm{Au} @ \mathrm{SiO}_{2}$ yolk-shell nanoparticles were employed as a catalyst for the reduction of $p$-nitrophenol by $\mathrm{NaBH}_{4}[29,30]$. The reduction did not occur in the absence of the yolk-shell catalysts. The reaction progress was quantitatively monitored by the decrease in UV absorption of $p$-nitrophenol at $400 \mathrm{~nm}$ and the simultaneous increase in the intensity of the UV absorption peak of the product, $p$-aminophenol, at $300 \mathrm{~nm}$. Au@SiO ${ }_{2}$ core-shell and yolk-shell nanoparticles with different core diameters were used for the catalytic reactions. The ratio of $C_{t}$ and $C_{0}$, where $C_{\mathrm{t}}$ and $C_{0}$ are $p$-nitrophenol concentrations at time $t$ and 0 , respectively, was measured from the ratio of the absorbances, $A_{\mathrm{t}}$ and $A_{0}$. As shown in Fig. 3(b), a linear relationship between $\ln \left(C_{\mathrm{t}} / C_{0}\right)$ and the reaction time was observed for all the catalysts. The reaction followed pseudo-first order kinetics, because the $\mathrm{BH}_{4}^{-}$ concentration remained almost constant during the reaction since an excess of $\mathrm{NaBH}_{4}$ was employed. From the slopes of these straight lines, the rate constants were estimated from diffusion-limited pseudo-first order kinetics using Eqs. (3) and (4). The concentrations of $p$-nitrophenol inside and outside the silica were assumed to be constant, and a concentration gradient was generated in the silica shell. In the equations

$$
\begin{gathered}
V_{\text {outside }}\left(C_{\text {out }, 0}-C_{\text {out }, \mathrm{t}}\right) / t=A_{\text {outside }} D_{\text {eff }} / l\left(C_{\text {out }}-C_{\text {in }}\right) \\
A_{\text {outside }} D_{\text {eff }} / l\left(C_{\text {out }}-C_{\text {in }}\right)=k C_{\text {in }} V_{\text {inside }}
\end{gathered}
$$

$l$ is the silica shell thickness ( $22 \mathrm{~nm}), V_{\text {outside }}$ and $A_{\text {outside }}$ are the volume and surface area of the catalyst particle $(R=82 \mathrm{~nm})$, and $V_{\text {inside }}$ is the volume of the vacancy inside the silica. $C_{\text {out }, 0}, C_{\text {out }, \text { t }}$ and $C_{\text {in }}$ are the concentrations outside the silica shell at $t=0$ and $t$, and the concentration inside the silica shell, respectively. 
$D_{\text {eff }}$ is the diffusion coefficient $\left(4.74 \times 10^{-19} \mathrm{~m}^{2} / \mathrm{s}\right) . C_{\text {in }}$ was calculated from Eq. (3), and the rate constant of the reduction reaction, $k$, was estimated from Eq. (4).

The resulting reaction rate constant decreased from $1.4 \times 10^{-2}$ to $3.9 \times 10^{-3} \mathrm{~s}^{-1}$, as the core diameter was reduced from 104 to $43 \mathrm{~nm}$. The reaction rate was faster for the larger gold cores due to their large surface area. However, the turnover frequency (TOF) of the catalysts increased nearly five times from 6.6 to $36 \mathrm{~s}^{-1}$ on reduction of the particle diameter from 104 to $43 \mathrm{~nm}$. This opposite trend reveals that the small cores with large surface roughness have more active surface sites such as edges and kinks, as observed in Fig. 2, which leads to higher reaction activity compared to that of the catalysts with larger cores. In the core-shell particles, the silica shell completely covered the gold surface, and reduced the total reaction rate. Freestanding gold nanoparticles, prepared by dissolving the silica shells with hydrogen fluoride, exhibited similar size-dependent reaction properties, but the total reaction rates were diminished by $\sim 40 \%$ with severe particle aggregation. Apparently, the outer silica shells in the $\mathrm{Au} @ \mathrm{SiO}_{2}$ yolk-shell nanoparticles enhanced the dispersion stability in polar solvents, so that high activity was maintained during solutionphase reactions. The catalyst particles were readily separated from the reaction mixture by simple centrifugation, and could be dispersed again in water by brief sonication.

\subsection{Tuning of porosity and diffusion rate of $\mathrm{Au} @ \mathrm{SiO}_{2}$ yolk-shell nanocatalysts}

The yolk-shell nanostructure is a structurally welldefined system, which is almost unique among heterogeneous catalysts. Therefore, precise chemical modification of both the metal cores and silica layers is possible, which should lead to enhanced catalytic properties. In general, the porosity of the support directly affects surface adsorption, catalyst dispersion, and diffusion rates of the reagents. It is known that the porosity can be readily controlled by adjusting the surfactants and reaction conditions during silica polymerization [31].

In the $\mathrm{Au} @ \mathrm{SiO}_{2}$ yolk-shell model catalysts, we tried to modify the silica shell layers by chemical treatment
[32]. Long alkyl chain siloxanes such as $\mathrm{C}_{18} \mathrm{TMS}$ (octadecyltrimethoxysilane) were used as a poregenerating reagent, a so-called "porogen", during silica coating on the gold spherical particles. The presence of the porogen led to a sparse silica network owing to the alkyl chains, and irregular pores were generated after calcination at high temperature [16, 33]. The molar ratio of $\mathrm{C}_{18} \mathrm{TMS}$ with respect to the silica precursor (tetraethoxysilane, TEOS) used in the reaction, ([C $\left.\left.\mathrm{C}_{18} \mathrm{TMS}\right] /[\mathrm{TEOS}]\right)$, was varied from 0.06 to $0.08,0.10$, and 0.12 . The gold particles were coated with silica shells using the Stöber method under otherwise identical conditions. The resulting $\mathrm{Au} @ \mathrm{SiO}_{2}$ core-shell nanoparticles had average core diameters of $102 \mathrm{~nm} \pm$ $8 \mathrm{~nm}$ and silica shell thicknesses of $17 \mathrm{~nm} \pm 2 \mathrm{~nm}$.

Selective etching of the gold cores by treatment with $\mathrm{KCN}$ afforded yolk-shell type nanostructures with average core sizes of 76-80 nm, as shown in Fig. 4 .

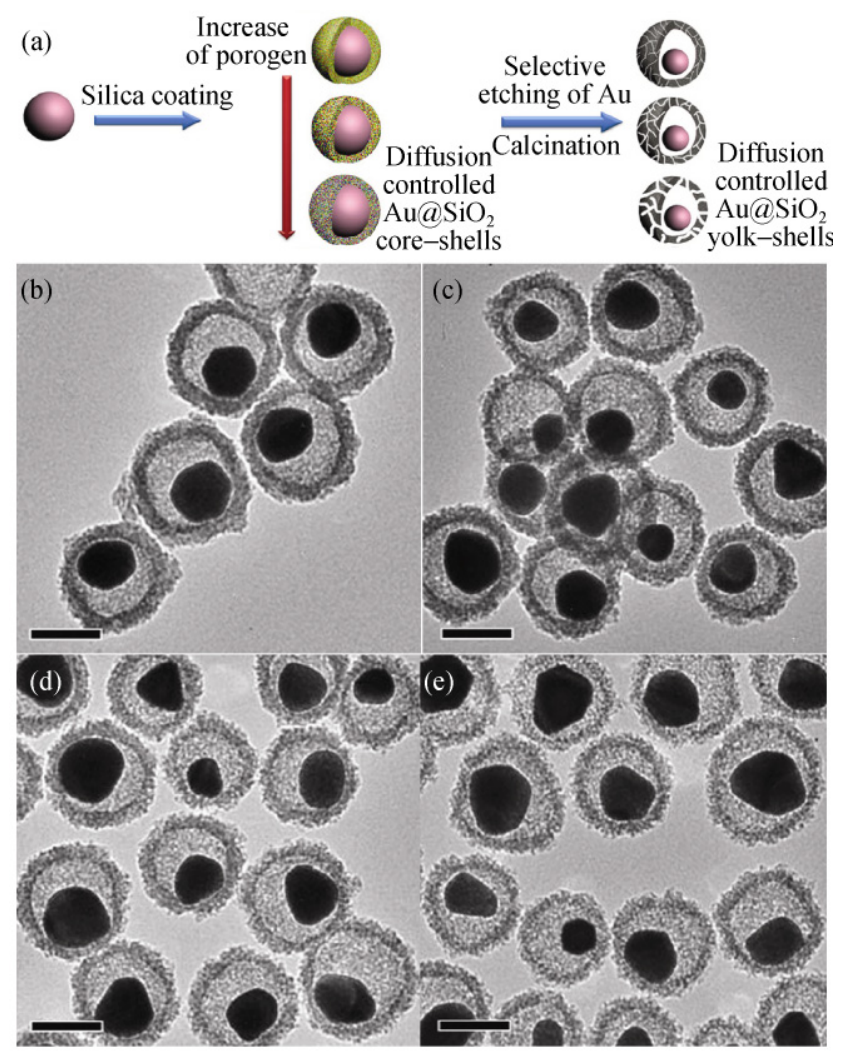

Figure 4 (a) Synthesis of $\mathrm{Au} @ \mathrm{SiO}_{2}$ yolk-shell nanocatalysts with controlled porosity. (b)-(e) TEM images of $\mathrm{Au} @ \mathrm{SiO}_{2}$ yolk-shell nanocatalysts; The $\left[\mathrm{C}_{18} \mathrm{TMS}\right] /[\mathrm{TEOS}]$ ratios used in the synthesis were (b) 0.06, (c) 0.08, (d) 0.10, and (e) 0.12; All scale bars represent $100 \mathrm{~nm}$. Reproduced with permission from Ref. [32]. Copyright American Chemical Society, 2008 
The diffusion coefficients and their dependence on the $\left[\mathrm{C}_{18} \mathrm{TMS}\right] /[\mathrm{TEOS}]$ ratio were evaluated from the changes in the surface plasmon resonance of the gold cores [15]. The UV-vis extinction shifts were monitored for dispersions of each of the yolk-shell particles in 2-propanol on addition of quinoline, as described above. Shifts of $6 \mathrm{~nm}$, from 598 to $604 \mathrm{~nm}$, were observed for all samples. The diffusion rate of each $\mathrm{Au} @ \mathrm{SiO}_{2}$ yolk-shell nanostructure was calculated from Eq. (2). When the $\left[\mathrm{C}_{18} \mathrm{TMS}\right] /[\mathrm{TEOS}]$ ratio was increased from 0.06 to 0.12 , the diffusion coefficient of the silica shells increased linearly as shown in Table 1, with an overall increase of more than threefold.

The reduction of $o$-nitroaniline by $\mathrm{NaBH}_{4}$ was selected as a model reaction that could show diffusioncontrolled kinetics with the $\mathrm{Au} @ \mathrm{SiO}_{2}$ yolk-shell nanocatalysts [30]. The reaction followed a pseudo-first order pathway in the presence of excess $\mathrm{BH}_{4}^{-}$. Strong UV-vis absorption peaks of o-nitroaniline were observed at 280 and $410 \mathrm{~nm}$, whereas the latter peak was completely absent after reduction to benzenediamine. The $\mathrm{Au} @ \mathrm{SiO}_{2}$ catalysts prepared without $\mathrm{C}_{18}$ TMS did not show any catalytic activity. As the porosity and diffusion coefficient of the silica shell increased, the TOF of the catalysts increased from 5.1 to $35 \mathrm{~s}^{-1}$, indicating that the reactions were essentially diffusion-limited through the porous silica shell layers. The reactions followed first-order kinetics in all cases, exhibiting a linear relationship between $\ln \left(C_{t} / C_{0}\right)$ and reaction time, as shown in Fig. 5 . The observed rate constants $\left(k_{\mathrm{obs}}\right)$ were directly estimated from the line slopes, and the rate constants on the gold surface $\left(k_{\mathrm{Au}}\right)$ could be calculated from Eq. (4). As

Table 1 Diffusion coefficients and turnover frequencies (TOFs) of the $\mathrm{Au} @ \mathrm{SiO}_{2}$ yolk-shell nanocatalysts ${ }^{\mathrm{a}}$

\begin{tabular}{ccc}
\hline$\left[\mathrm{C}_{18} \mathrm{TMS}\right] /[\mathrm{TEOS}]$ & $\begin{array}{c}\text { Diffusion coefficient } \\
\left(\mathrm{m}^{2} / \mathrm{s}\right)\end{array}$ & $\mathrm{TOF}\left(\mathrm{s}^{-1}\right)^{\mathrm{b}}$ \\
\hline 0.06 & $5.9 \times 10^{-19}$ & 5.1 \\
0.08 & $8.5 \times 10^{-19}$ & 11 \\
0.10 & $1.1 \times 10^{-18}$ & 14 \\
0.12 & $2.1 \times 10^{-18}$ & 35 \\
\hline
\end{tabular}

\footnotetext{
${ }^{\mathrm{a}}$ The same number of particles $\left(1.1 \times 10^{10}\right)$ was used for each reaction;

${ }^{\mathrm{b}}$ TOF was calculated from the corresponding spheres using the atomic diameter (135 pm) of bulk gold metal. Reproduced with permission from Ref. [32]. Copyright American Chemical Society, 2008.
}

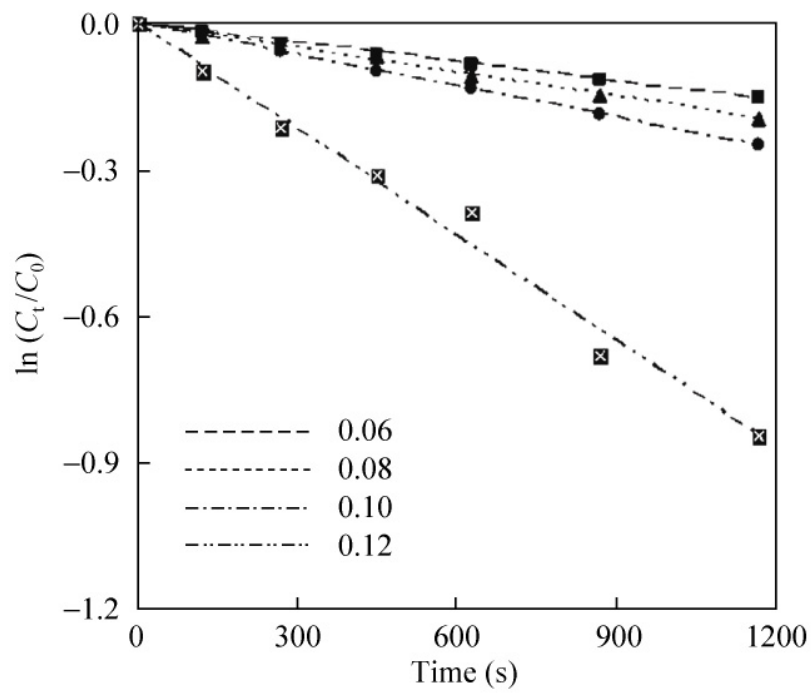

Figure 5 Plots of $\ln \left(C_{t} / C_{0}\right)$ versus time and the rate constants $\left(k_{\mathrm{obs}}\right)$ for yolk-shell nanocatalysts. Reproduced with permission from Ref. [32]. Copyright American Chemical Society, 2008

Table 2 Rate constants $\left(k_{\mathrm{obs}}\right.$ and $\left.k_{\mathrm{Au}}\right)$ for $\mathrm{Au} @ \mathrm{SiO}_{2}$ yolk-shell nanocatalysts $^{\mathrm{a}}$

\begin{tabular}{ccc}
\hline$\left[\mathrm{C}_{18} \mathrm{TMS}\right] /[\mathrm{TEOS}]$ & $k_{\mathrm{obs}}\left(\mathrm{s}^{-1}\right)$ & $k_{\mathrm{Au}}\left(\mathrm{s}^{-1}\right)$ \\
\hline 0.06 & $1.3 \times 10^{-4}$ & $1.1 \times 10^{-3}$ \\
0.08 & $1.6 \times 10^{-4}$ & $1.4 \times 10^{-3}$ \\
0.10 & $2.1 \times 10^{-4}$ & $1.3 \times 10^{-3}$ \\
0.12 & $7.2 \times 10^{-4}$ & $1.4 \times 10^{-3}$ \\
\hline
\end{tabular}

${ }^{\mathrm{a}}$ The same number of particles $\left(1.1 \times 10^{10}\right)$ was used for each reaction. Reproduced with permission from Ref. [32]. Copyright American Chemical Society, 2008.

shown in Table 2, the value of $k_{\text {obs }}$ increased 5.5 times when the shell porosity was increased by increasing the $\left[\mathrm{C}_{18} \mathrm{TMS}\right] /[\mathrm{TEOS}]$ ratio from 0.06 to 0.12 . The value of $k_{\mathrm{Au}}$ was almost constant, $\sim 1.3 \times 10^{-3} \mathrm{~s}^{-1}$, for the different samples. This indicates that the reaction rate is only dependent upon the diffusion rate through the silica layers.

\subsection{Tuning of surface functionality of the gold cores in $\mathrm{Au} @ \mathrm{SiO}_{2}$ yolk-shell nanocatalysts}

In nature, enzymes are the most efficient catalysts. Some reactions normally requiring high pressure and temperature can be performed under ambient conditions in the presence of naturally occurring enzymes. Enzymes have reaction pockets involving active metal centers, and the amino acid residues close to the 
metal centers interact with the reactants and reaction intermediates, stabilizing the structures and lowering activation energy during the reaction. Special functional groups in the residues behave as molecular recognition sites to provide excellent selectivity as well as high activity in specific reactions [34].

We tried to mimic these enzyme structures by adding functionality on the gold surface, in order to enhance total reaction rates. Thiols were selectively bound to the gold surface without any interaction with the silica [35], and then a bifunctional ligand such as 3-mercaptopropionic acid (3-MPA) could be used to decorate the gold surface with terminal carboxylic acid groups through the formation of strong $\mathrm{S}-\mathrm{Au}$ bonds (Fig. 6(a)) [36]. The $\mathrm{Au} @ \mathrm{SiO}_{2}$ yolk-shell nanocatalysts modified with 3-MPA (Fig. 6(b)) were employed as catalysts for the reduction of o-nitroaniline with $\mathrm{NaBH}_{4}$. As shown in Fig. 6(c), the rate constant reached a maximum value of $1.4 \times 10^{-3}$ $\mathrm{s}^{-1}$, some 2.4 times larger than the value for the unfunctionalized catalyst. It is possible that the carboxylate group of 3-MPA present under the basic conditions of the reaction can form strong hydrogen bonds with $o$-nitroaniline [37], and give a longer retention time of the reactants on the active gold surface yielding higher reaction rates. The rate constant

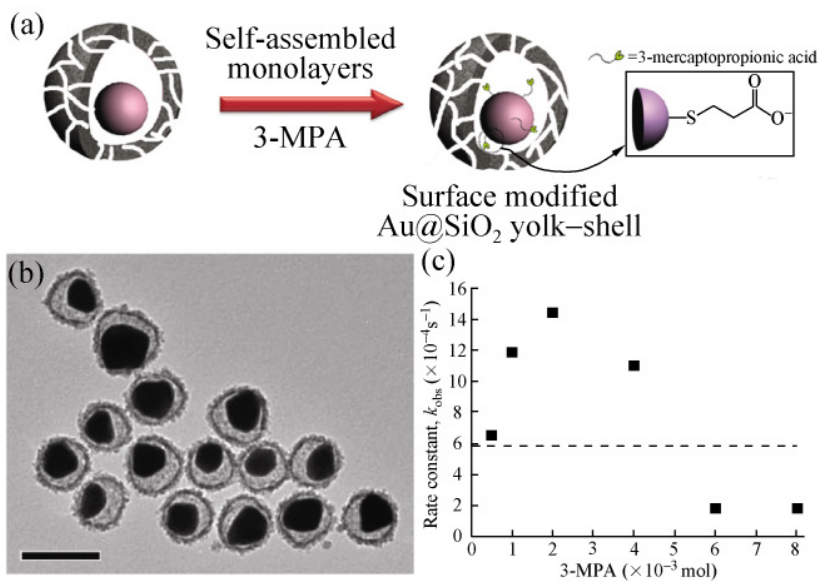

Figure 6 (a) Chemical functionalization of $\mathrm{Au} @ \mathrm{SiO}_{2}$ yolk-shell nanocatalysts; (b) TEM image of $\mathrm{Au} @ \mathrm{SiO}_{2}$ yolk-shell nanocatalysts after the addition of 3-MPA (the scale bar represents $200 \mathrm{~nm}$ ) and (c) plots of the rate constant for reduction of $o$-nitroaniline with $\mathrm{NaBH}_{4}$ versus the amount of 3-MPA used for functionalization (the dotted line represents the rate constant $(5.8 \times$ $10^{-4} \mathrm{~s}^{-1}$ ) of the unfunctionalized catalyst). Reproduced with permission from Ref. [32]. Copyright American Chemical Society, 2008 decreased at high 3-MPA concentrations, presumably because of blocking of the exposed gold surface to the reactants.

By a combination of maximizing the shell porosity and the optimum core functionalization, the $\mathrm{Au} @ \mathrm{SiO}_{2}$ yolk-shell catalysts exhibited a maximum 13-fold enhancement in rate constant compared to the value $\left(1.1 \times 10^{-4} \mathrm{~s}^{-1}\right)$ for the unmodified catalyst. This clearly shows that appropriate chemical treatment of the catalyst structure can lead to large increases in reaction activity.

\section{High temperature stability: $\mathrm{Ni}_{\mathrm{SiO}}$ yolk- shell nanocatalysts for steam methane reforming}

As well as reaction activity and selectivity, thermal stability and reusability are important practical issues affecting the use of heterogeneous catalysts. Most industrially valuable reactions are carried out at high temperature and pressure. Under these conditions, small nanoparticles are readily sintered, becoming large clusters, which reduces the surface area of the catalysts and consequently leads to a decrease in reactivity. Choosing appropriate support materials and additives to prevent this sintering problem demand a large number of trial-and-error reaction tests.

If the active metal particles cannot approach close to one other, particle agglomeration will be essentially eliminated. In the case of active metal particles inside mesoporous supports, the movement of particles is restricted inside the pore channels, and thereby good particle dispersion is maintained at relatively high temperature. However, the particles are not sufficiently stable to prevent sintering due to surface melting and migration at temperatures exceeding $>623 \mathrm{~K}$ [11].

The yolk-shell structure should be an excellent catalyst for high temperature reactions. The active nanoparticles are completely surrounded by the robust silica shells, and the particles cannot approach neighboring particles even at temperatures higher than that of surface melting. Because of the porous silica shells, the reactants and products can still migrate in and out of the catalyst structure, and the reaction activity will not decrease during reactions 
under harsh conditions. If coke is formed and blocks the active surface, thermal treatment with oxygen will remove it, and hydrogen reduction can regenerate a clean catalyst surface. We discuss this thermal stability issue using $\mathrm{Ni@SiO}$ 2 yolk-shell nanocatalysts, and show a promising application of the catalysts in steam methane reforming, a reaction that generates an alternative energy source-hydrogen-in high efficiency [39].

\subsection{Synthesis and characterization of $\mathrm{Ni}_{\mathrm{SiO}}$ yolk-shell nanocatalysts}

The synthesis of $\mathrm{Ni@SiO}$, yolk-shell nanostructures involved similar steps to those for the $\mathrm{Au} @ \mathrm{SiO}_{2}$ yolkshell nanocatalysts (Fig. 7(a)). Nickel nanoparticles were synthesized through a modified polyol process in the presence of PVP. The resulting nanoparticles were spheres with an average diameter of $37 \mathrm{~nm} \pm$ $3 \mathrm{~nm}$, and were aligned to become necklace-like structures [40]. The particles were coated with silica using the Stöber method (Fig. 7(b)). In order to generate
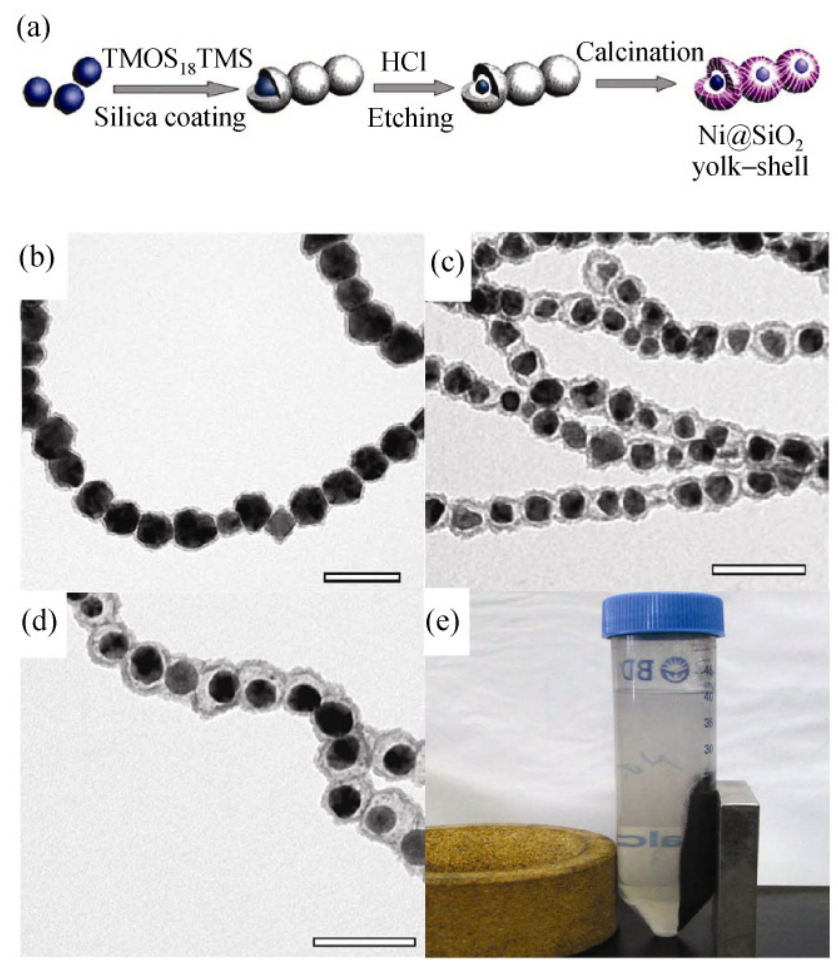

Figure 7 (a) Fabrication of $\mathrm{Ni@} \mathrm{SiO}_{2}$ yolk-shell nanocatalysts; (b) TEM images of $\mathrm{Ni} @ \mathrm{SiO}_{2}$ core-shell nanocatalysts; $\mathrm{Ni} @ \mathrm{SiO}_{2}$ yolk-shell nanocatalysts (c) before and (d) after calcination; (e) magnetic separation of $\mathrm{Ni} @ \mathrm{SiO}_{2}$ nanocatalysts in ethanol. All scale bars represent $100 \mathrm{~nm}$. Adapted from Ref. [39] pores in the silica shell, $\mathrm{C}_{18}$ TMS was added to the reaction mixture during the coating process. The average thickness of the silica shells was measured to be $7.1 \mathrm{~nm} \pm 0.4 \mathrm{~nm}$. The nickel cores in the silicacoated nickel nanoparticles were partially etched by aqueous hydrochloric acid. Precise adjustment of the hydrochloric acid concentration allowed nickel cores with different diameters to be obtained. Fig. 7(c) shows that the nickel cores form a yolk-shell structure with silica, and the silica shells are connected with neighboring ones to form a spawn-like structure. The average core size was estimated to be $31 \mathrm{~nm} \pm 3 \mathrm{~nm}$.

The $\mathrm{Ni@SiO}$ yolk-shell nanoparticles were treated at $773 \mathrm{~K}$ for $2 \mathrm{~h}$ under a hydrogen atmosphere. Even after the high temperature treatment, the structure maintained its yolk-shell morphology without agglomeration, as shown in Fig. 7(d). The nickel loading content was measured to be $89 \mathrm{wt} \%$; the material is thus unique in allowing the nanostructure to be preserved at such a high metal content. The CO adsorption isotherm exhibited a Langmuir-type behavior with a surface area of $29.0 \mathrm{~m}^{2} / \mathrm{g}$. The average metal core size was estimated to be $23.2 \mathrm{~nm}$, in good agreement with the particle size of $24.0 \mathrm{~nm}$ measured from the TEM images. Based on $\mathrm{N}_{2}$ adsorption results, the estimated Brunauer-Emmett-Teller (BET) surface area was $275 \mathrm{~m}^{2} / \mathrm{g}$. The average pore size calculated from the desorption branch by the Barrett-JoynerHalenda (BJH) method was $3.9 \mathrm{~nm}$.

The synthesis of $\mathrm{Ni@SiO}$, yolk-shell nanoparticles could be scaled up to gram quantities, and separation from self-seeded silica particles was very easy by using a magnet (Fig. 7(e)).

\subsection{Steam methane reforming reactions with $\mathrm{Ni@SiO}{ }_{2}$ yolk-shell nanocatalysts}

Hydrogen is regarded as a next-generation energy source for substitution of fossil fuels [41]. Ideally hydrogen should be generated by carbon-free technology, but this has not yet been fully developed and reached commercialization. In the current situation, hydrogen generation by the most effective way is important in order not to waste valuable energy. Methane reforming with steam or carbon dioxide is a highly efficient method for generating hydrogen gas [42]. Nickel nanoparticles on supports 
are known to be the most suitable catalyst for steam reforming reactions, because of their reasonable activity with an affordable price [43]. But the serious problem of nickel catalysts is catalyst deactivation either by coke formation and/or by particle sintering [44]. Conventional metal catalysts are readily agglomerated under steam methane reforming conditions at high temperature. The yolk-shell type of catalyst design should resolve this sintering problem, and enhance the catalyst life-time and reusability for such high temperature reactions.

The $\mathrm{Ni} @ \mathrm{SiO}_{2}$ yolk-shell nanocatalysts were employed for steam methane reforming with a high steam to methane ratio to prevent severe carbon deposition. Under these reaction condition $\left(\mathrm{H}_{2} \mathrm{O}: \mathrm{CH}_{4}=4: 1\right)$ at $973 \mathrm{~K}$ the yolk-shell catalysts exhibited a constant methane conversion of $>90 \%$ for $4 \mathrm{~h}$, nearly approaching the theoretical maximum value (Fig. 8). The catalysts were regenerated by hydrogen treatment at $973 \mathrm{~K}$ for $1 \mathrm{~h}$, and were used three times without any loss of methane conversion. In contrast, conventional $\mathrm{Ni} /$ mesostructured cellular foam (MCF) catalysts that were prepared by impregnation of nickel on MCFs [45] showed a sudden drop of methane conversion to $60 \%$ within $90 \mathrm{~min}$, and maintained this lower value even after regeneration of the catalysts. After being reused three times, the $\mathrm{Ni} @ \mathrm{SiO}_{2}$ yolk-shell nanocatalysts did not change their yolk-shell structure, whereas the Ni/MCF catalysts became sintered to yield huge nickel clusters segregated from the silica matrix (Fig. 9).

We also compared the activity of state-of-the-art commercial catalysts (Haldor Topsøe) with our yolk-
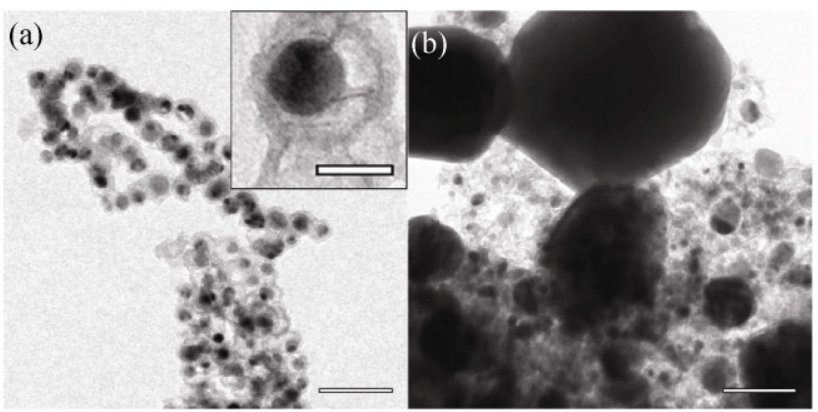

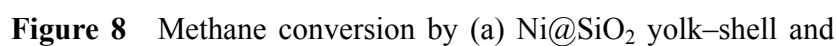
$\mathrm{Ni} / \mathrm{MCF}$ catalysts $\left(\mathrm{GHSV}=100000 \mathrm{~h}^{-1} ; \mathrm{H}_{2} \mathrm{O}: \mathrm{CH}_{4}=4: 1\right)$, and by (b) $\mathrm{Ni} / \mathrm{SiO}_{2}$ yolk-shell and commercial catalysts $\left(\mathrm{GHSV}=25000 \mathrm{~h}^{-1}\right.$; $\mathrm{H}_{2} \mathrm{O}: \mathrm{CH}_{4}=3: 1$ ); Dotted lines indicate methane conversion at thermodynamic equilibrium. Adapted from Ref. [39]

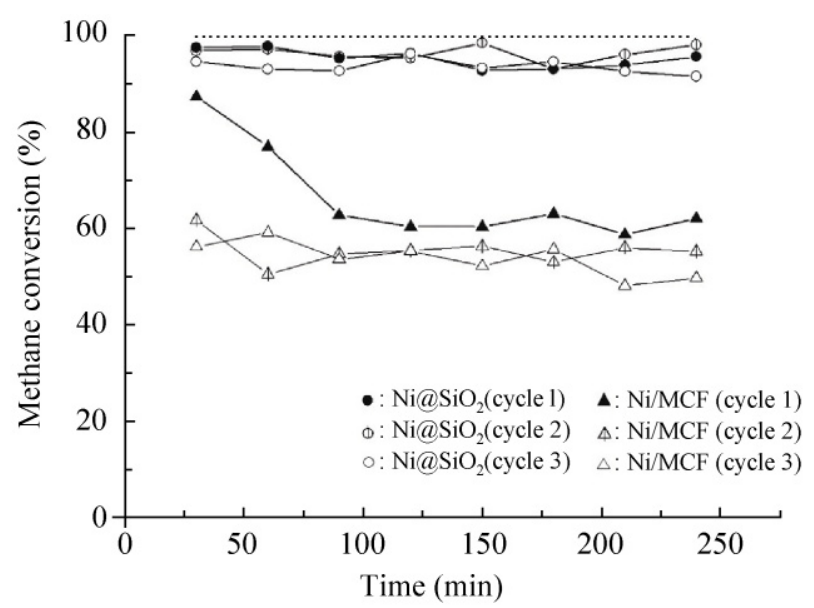

(a)

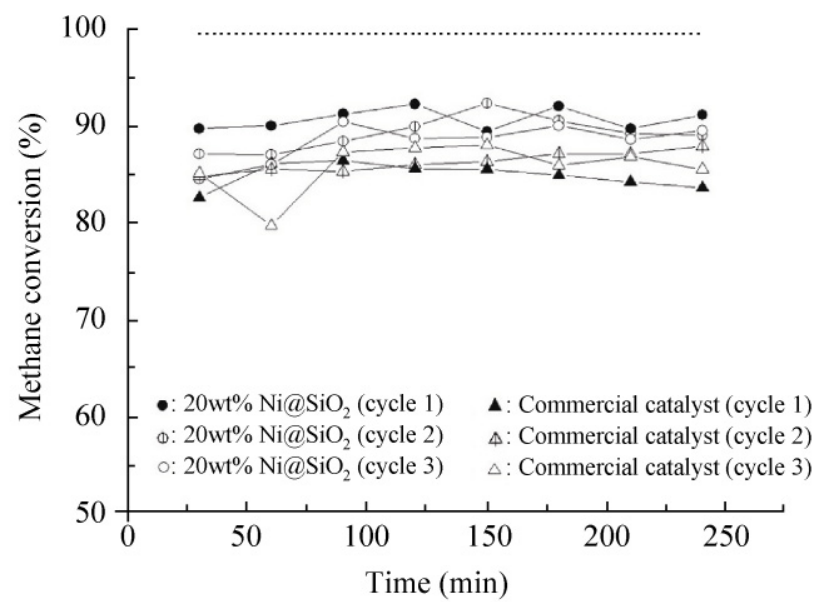

(b)

Figure 9 TEM images of (a) $\mathrm{Ni@SiO}$ yolk-shell and (b) $\mathrm{Ni} / \mathrm{MCF}$ catalysts after being used three times in steam methane reforming reactions; The bars in (a) and (b) represent $100 \mathrm{~nm}$ and (inset) $20 \mathrm{~nm}$. Adapted from Ref. [39]

shell nanocatalysts. The commercial catalyst is known to be composed of $\mathrm{Ni} / \mathrm{MgAl}_{2} \mathrm{O}_{4}$, which is the best bifunctional composition for reforming reactions. For the purposes of precise comparison, the yolk-shell nanocatalyst was diluted with MCF to a nickel loading of $20 \mathrm{wt} \%$ [46], and the reactions were carried out with a 3:1 steam to methane ratio, as is actually used in industry. Both catalysts exhibited methane conversion of $\sim 70 \%$, which remained almost constant over three reaction cycles. Remarkably, our yolk-shell nanocatalysts showed even better activity than the commercial ones, with excellent stability, although the catalyst structure and the composition were not fully optimized. This indicates that a rational catalyst design is a powerful way to enhance catalytic perfor- 
mance in terms of high activity, thermal stability, and recyclability.

\section{High activity and reusability: $\mathrm{Ni} \mathrm{SiO}_{2}$ yolk-shell nanocatalysts with tiny metal cores for catalytic hydrogen transfer reactions}

In heterogeneous catalytic reactions, numerous factors influence reaction activity and selectivity, such as active particle diameter, metal loading, support structure, additives, reactant and product concentrations, solvents, and reaction conditions $[1,3]$. It is generally believed that small particles show high activity because of their high surface area and high density of active sites including edges, vertices, kinks, and steps on the surface $[47,48]$. In terms of the particle size, the size effect begins to influence total reactivity when the size is smaller than $10 \mathrm{~nm}$, and it has a dominant influence on the reaction properties if the size is less than $5 \mathrm{~nm}$ [49]. Therefore, most heterogeneous catalysts that are commercially available have active metal nanoparticles with diameters of a few nanometers in order to optimize reaction activity.

In this review, we have introduced the $\mathrm{Au} @ \mathrm{SiO}_{2}$ yolk-shell structure as a model catalyst to induce electron relay from $\mathrm{BH}_{4}{ }^{-}$to $p$-nitrophenol, and employed $\mathrm{Ni@SiO}$, yolk-shell catalysts in steam methane reforming. The reforming reactions were carried out at a high temperature of $973 \mathrm{~K}$, and therefore the particle size was so crucial because small particles readily agglomerate under such conditions. However, there are many reactions such as $\mathrm{CO}$ oxidation and solution-phase organic transformations which take place under relatively mild conditions, and here size effects can play a dominant role. Reduction of the metal core size is definitely required if the yolk-shell nanocatalysts are to be employed to catalyze such organic reactions. Here we demonstrate yolkshell nanocatalysts with tiny cores having a $3 \mathrm{~nm}$ diameter and their high activity for hydrogen transfer from 2-propanol to acetophenone [50].

\subsection{Synthesis of $\mathrm{Ni}(3 \mathrm{~nm}) @ \mathrm{SiO}_{2}$ yolk-shell nanocatalysts by the microemulsion method}

In the previous synthesis, the $\mathrm{Ni} @ S i O_{2}$ yolk-shell nanocatalysts had core diameters of 31 and $24 \mathrm{~nm}$, which are large compared to common active catalysts with diameters of a few nanometers [39]. However, reducing the core size without changing the synthetic process is not trivial. Formation of a silica coating via the Stöber method was generally used for metal nanoparticles with diameters larger than $10 \mathrm{~nm}$, and generated thick layers with thicknesses of $>20 \mathrm{~nm}$ [27]. In addition, etching of the metal cores is not a viable way to reduce the core diameters to less than several nanometers - the addition of excess etchants led to complete dissolution of the cores.

Instead, a microemulsion method in organic media was employed to generate a thin silica coating on tiny metal nanoparticles [51]. For this process, the nickel particles were synthesized in the presence of trioctylphosphine and oleylamine in organic solvents [52]. The product consisted of spherical nanoparticles with an average diameter of $5.1 \mathrm{~nm} \pm 0.3 \mathrm{~nm}$ as shown in Fig. 10(b). A dispersion of the nickel nanoparticles
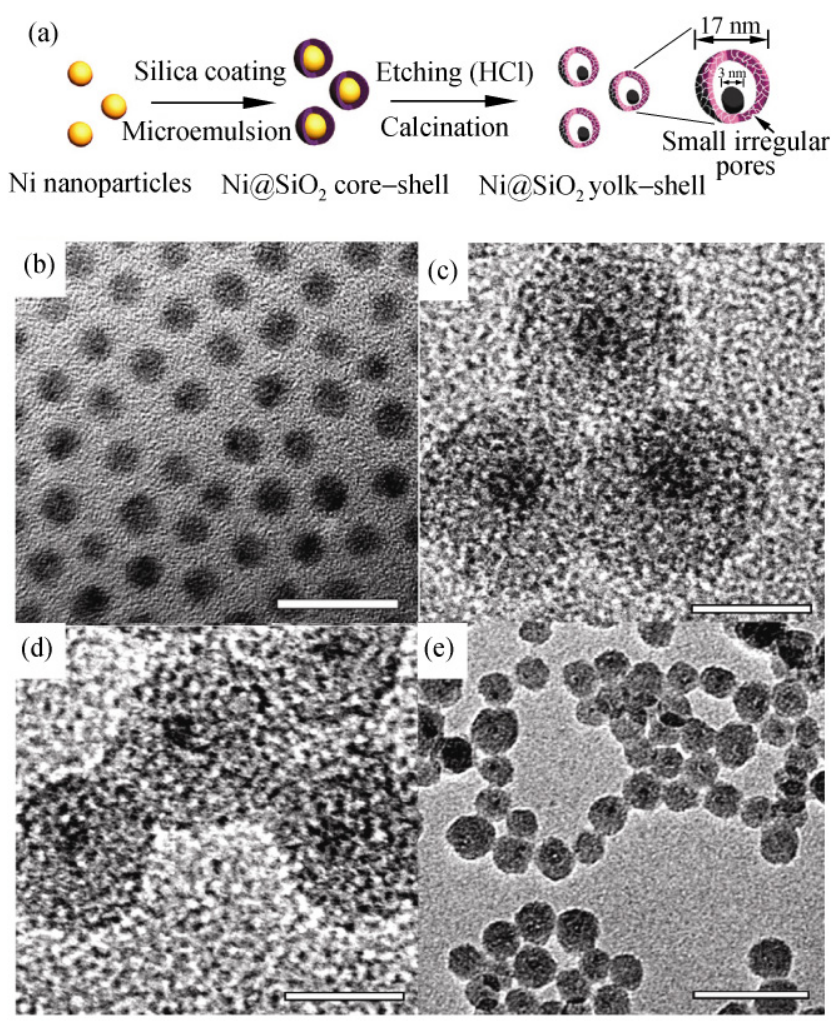

Figure 10 (a) Synthesis of $\mathrm{Ni} @ \mathrm{SiO}_{2}$ yolk-shell nanocatalysts with tiny nickel cores; TEM images of (b) Ni nanoparticles and (c) $\mathrm{Ni} @ \mathrm{SiO}_{2}$ core-shell nanoparticles, and $\mathrm{Ni} @ \mathrm{SiO}_{2}$ yolk-shell nanocatalysts (d) before and (e) after calcination; The bars represent (b) $20 \mathrm{~nm}$, (c) and (d) $10 \mathrm{~nm}$, and (e) $100 \mathrm{~nm}$. Reproduced with permission from Ref. [50]. Copyright American Chemical Society, 2010 
in cyclohexene was mixed with polyoxyethylene (9) nonylphenylether (Igepal CO-630) in the presence of ammonia, and a mixture of the TEOS and $\mathrm{C}_{18}$ TMS was added to the reaction mixture, followed by stirring at room temperature for $1 \mathrm{~h}$. Fig. 10(c) shows the successful formation of the $\mathrm{Ni@SiO}{ }_{2}$ core-shell nanoparticles with uniform silica layers having an average thickness of $6.1 \mathrm{~nm} \pm 0.5 \mathrm{~nm}$. The nickel cores were slightly etched by hydrogen chloride to reduce the nickel core diameter to $2.9 \mathrm{~nm} \pm 0.3 \mathrm{~nm}$ and finally yielded the $\mathrm{Ni} @ \mathrm{SiO}_{2}$ yolk-shell nanostructure (Fig. 10(d)). The overall diameters of the core-shell andyolk-shell nanoparticles were $17 \mathrm{~nm}$, much smaller than those ( $55 \mathrm{~nm}$ ) prepared by the Stöber method [39].

After high temperature treatment at $773 \mathrm{~K}$, the $\mathrm{Ni} @ \mathrm{SiO}_{2}$ yolk-shell nanoparticles maintained their original structure as shown in Fig. 10(d). The $\mathrm{N}_{2}$ sorption isotherms of the silica hollow shells exhibited features typical of a mesoporous material, with the surface area and total pore volume being $195 \mathrm{~m}^{2} / \mathrm{g}$ and $0.38 \mathrm{~cm}^{3} / \mathrm{g}$, respectively. The nickel loading content was measured to be $18 \mathrm{wt} \%$ by energy-dispersive X-ray fluorescence (EDXRF) spectroscopy.

The $\mathrm{Ni}(3 \mathrm{~nm}) @ \mathrm{SiO}_{2}$ nanocatalysts are not suitable for high temperature reactions at $>573 \mathrm{~K}$, owing to total melting of the tiny core particles. This catalyst structure is excellent for solution-phase organic reactions, however, because the reactions take place at temperatures less than solvent boiling points. The small size of the metal cores is expected to be a powerful way to maximize the reactivity under such mild conditions. The main benefit of the yolk-shell structure, that particle aggregation during the reactions is prevented, should still apply.

\subsection{Hydrogen transfer reaction from 2-propanol to acetophenone catalyzed by $\mathrm{Ni@SiO}$ yolk-shell nanocatalysts}

The $\mathrm{Ni} @ S i O_{2}$ yolk-shell nanocatalysts were employed for hydrogen transfer reactions of acetophenone (Table 3) [53, 54]. 2-Propanol was used as a hydrogen donor, and the reaction conditions were at 353-423 K in the presence of $10 \mathrm{~mol} \%-20 \mathrm{~mol} \%$ of $\mathrm{NaOH}$. The amount of the catalyst was $0.03 \mathrm{~mol} \%-0.05 \mathrm{~mol} \%$ with respect to the substrate concentration.
Table 3 Hydrogen transfer of acetophenone to 1-phenylethanol catalyzed by $\mathrm{Ni@} \mathrm{SiO}_{2}$ yolk-shell nanocatalysts

\begin{tabular}{|c|c|c|c|c|c|}
\hline Entry & $\begin{array}{c}\text { Catalyst } \\
(\mathrm{mol} \%)\end{array}$ & $\begin{array}{l}\text { Temp. } \\
\text { (K) }\end{array}$ & $\begin{array}{l}\text { Time } \\
\text { (h) }\end{array}$ & $\begin{array}{c}\text { Base } \\
(\mathrm{mol} \%)\end{array}$ & $\begin{array}{l}\text { Conv. } \\
(\%)^{\mathrm{a}}\end{array}$ \\
\hline 1 & 0.05 & 423 & 0.5 & 20 & 93 \\
\hline 2 & 0.05 & 373 & 0.5 & 20 & 58 \\
\hline 3 & 0.05 & 373 & 1 & 20 & 92 \\
\hline 4 & 0.05 & 353 & 1 & 20 & 61 \\
\hline 5 & 0.05 & 373 & 1 & 10 & 68 \\
\hline 6 & 0.05 & 373 & 2 & 10 & 87 \\
\hline 7 & 0.03 & 423 & 0.5 & 20 & 90 \\
\hline 8 & 0.03 & 373 & 0.5 & 20 & 83 \\
\hline
\end{tabular}

${ }^{\mathrm{a}}$ Determined by ${ }^{1} \mathrm{H}-\mathrm{NMR}$ spectroscopy; Yields are based on the amount of acetophenone used. Adapted from Ref. [50]

The yield of 1-phenylethanol from acetophenone was found to be highly dependent on the reaction temperature, amount of base, and catalyst loading. Reaction at high temperature exhibited high conversion efficiency (entries 1-4 in Table 3). Lower base concentrations diminished the yield (entries 5 and 6). A catalyst loading of $0.03 \mathrm{~mol} \%$ with respect to the substrate concentration was still effective for the reactions (entries 7 and 8). In particular, the reaction conditions of $0.03 \mathrm{~mol} \%$ of catalysts and $20 \mathrm{~mol} \%$ of base at $423 \mathrm{~K}$ gave a $90 \%$ yield within $30 \mathrm{~min}$ without any by-products (entry 7), and these were chosen as the standard conditions for further studies. The TOF was calculated to be $6000 \mathrm{~h}^{-1}$, which is more than an order of magnitude higher than the values $\left(100-500 \mathrm{~h}^{-1}\right)$ using heterogeneous nickel catalysts $[53,54]$, where under the standard reaction condition, the catalyst loading was $10 \mathrm{~mol} \%-20 \mathrm{~mol} \%$ with respect to that of the substrate.

The remarkable activity of the $\mathrm{Ni@SiO}$ yolk-shell nanocatalysts can be mainly attributed to the small size of the particles associated with the absence of aggregation and the clean surfaces. Freestanding catalyst nanoparticles are usually aggregated, and their active surface area decreases after repeated heterogeneous catalytic reactions. Severe aggregation can be prevented 
if the particle surface is intensively passivated by surfactants, but a large amount of the surfactant blocks the active sites and lowers the reaction activity Since the surfactants on the $\mathrm{Ni} @ \mathrm{SiO}_{2}$ yolk-shell nanocatalyst surfaces were removed by high temperature treatment before the reaction, the surface is sufficiently clean to carry out the reaction effectively. The surfactants can be successfully removed by thermal treatment without giving any aggregation of the active cores of the nanocatalysts.

Because of the stable yolk-shell structure, the $\mathrm{Ni} @ \mathrm{SiO}_{2}$ yolk-shell nanocatalysts could be recycled several times without any loss of conversion yields. In marked contrast, with the freestanding nanoparticles the reaction yield dropped to $\sim 60 \%$ after recycling.

Under the standard conditions, a variety of ketones were successfully reduced with high efficiencies to the corresponding alcohols by using the $\mathrm{Ni@SiO}$ yolk-shell nanocatalysts. Cyclohexanone was reduced by 2 -propanol in $94 \%$ yield. Various alky aryl ketones were transformed to hydrogenated products in high yields, but diaryl ketones gave lower yields because of their bulkiness. Substituted acetophenones were also converted to alcohols, and the reaction yields were affected by the electronic properties and the position of the substitutents.

These excellent catalytic performances indicate that the yolk-shell nanostructure with tiny metal cores is an excellent catalyst scaffold for various heterogeneous organic transformations with high activity and reusability.

\section{A new nickel-on-silica hybrid structure: Chemical transformation of $\mathrm{Ni} @ \mathrm{SiO}_{2}$ nano- particles}

The metal@silica yolk-shell nanostructure has many advantages as a nanocatalyst for various gas- and solution-phase reactions. However, such a yolk-shell nanostructure is not the only bifunctional structure which enhances catalytic properties. Many other combinations of metal nanoparticles and a silica framework are possible, but effective stabilization of the active metal nanoparticles by the silica structure has to be considered in any design of a bifunctional catalyst.
Metal nanoparticles-on-silica spheres are one of the possible candidates for nanocatalysts. In this structure, the active particles are partially buried in the silica sphere, and thereby the particles are not mobile on the silica surface even at high temperature. The remainder of the metal surface is exposed, and is where the chemical reaction occurs. The advantage of such a structure is that there are no diffusion barriers. The reactants can freely approach the catalyst surface and undergo reaction. The active metal particles have strong chemical and mechanical interactions with the silica framework, which gives high stability during the reaction. The metal-on-silica bifunctional structure was found to be very hard to fabricate by surface treatment of silica spheres. However this structure could be obtained by transformation of $\mathrm{Ni@SiO}$ core-shell nanoparticles by hydrothermal and hydrogen reduction reactions (Fig. 11(a)) [55].

The $\mathrm{Ni@SiO}$ core-shell nanoparticles were synthesized by silica coating of nickel nanoparticles
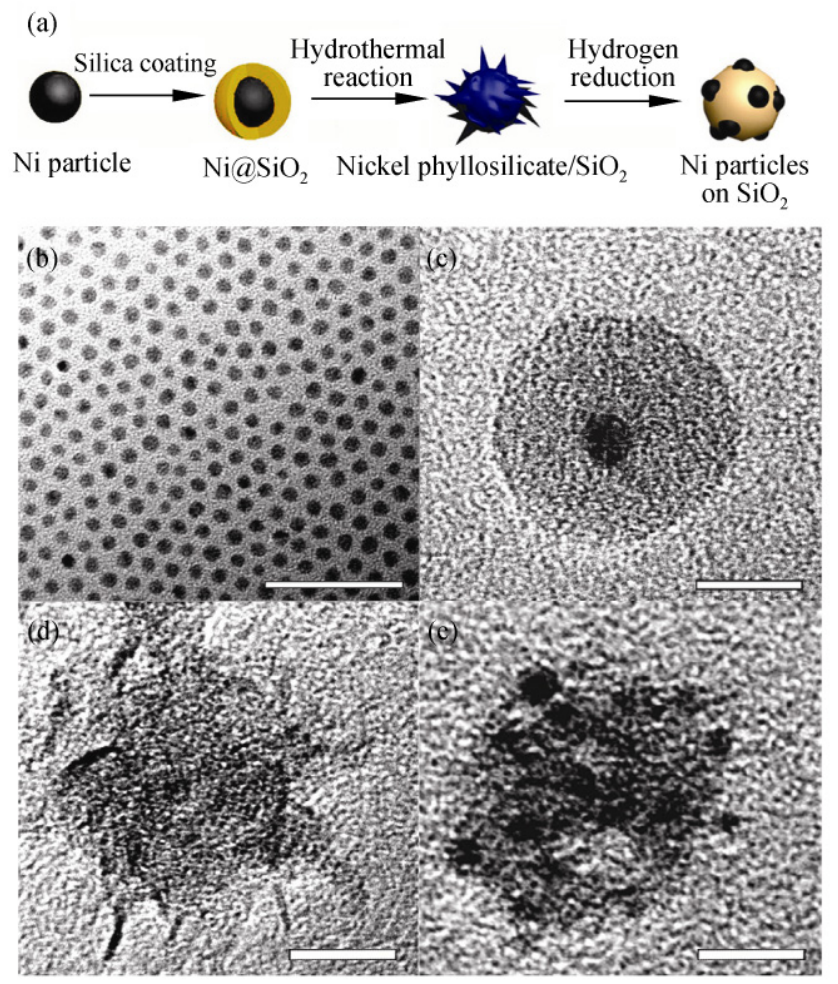

Figure 11 (a) Chemical transformation and subsequent morphology changes of nickel-silica hybrid nanoparticles; TEM images of (b) Ni, (c) Ni@SiO ${ }_{2}$, (d) nickel phyllosilicate/ $\mathrm{SiO}_{2}$, and (e) nickel-on-silica nanostructures; The bars represent (b) $50 \mathrm{~nm}$ and (c)-(e) $10 \mathrm{~nm}$. Adapted from Ref. [55]

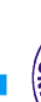

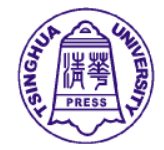

黑 Springer 
through the microemulsion method [51]. The silica layers were evenly coated on the outside of the nickel cores, and the resulting core-shell structure was spherical, as shown in Figs. 11(b) and 11(c). The average diameter of the nickel cores, the average thickness of the silica layers, and the overall diameter of the core-shell particles were estimated to be $5.3 \mathrm{~nm} \pm 0.2 \mathrm{~nm}, 9.2 \mathrm{~nm} \pm 1.1 \mathrm{~nm}$, and $26 \mathrm{~nm} \pm 2 \mathrm{~nm}$, respectively.

The $\mathrm{Ni} @ \mathrm{SiO}_{2}$ core-shell particles were converted to the branched spheres by refluxing in water under weakly basic conditions ( $\mathrm{pH}=9.6)$. Fig. 11(d) shows that the spheres with an average diameter of $25 \mathrm{~nm} \pm$ $1 \mathrm{~nm}$ have branches of $5 \mathrm{~nm}$ in length and $1 \mathrm{~nm}$ in thickness. X-ray diffraction data indicate that the particles are composed of nickel phyllosilicate (pecoraite $\left.\mathrm{Ni}_{3} \mathrm{Si}_{2} \mathrm{O}_{5}(\mathrm{OH})_{4}\right)$ and silica. Such branched morphology is typically observed in nickelobtained by be successfully removed by thermal phyllosilicate phases [56,57]. These branched particles were transformed to $\mathrm{Ni} / \mathrm{SiO}_{2}$ nanoparticles by high temperature treatment at $973 \mathrm{~K}$ for $10 \mathrm{~h}$ under a reducing environment. The TEM image in Fig. 11(e) clearly shows that tiny nanoparticles are located on the surface of silica spheres, matching the morphology of the nickel-on-silica structure that we originally designed. The average diameter of the silica spheres is $24 \mathrm{~nm} \pm$ $1 \mathrm{~nm}$, and that of the tiny nickel particles is $\sim 3 \mathrm{~nm}$ with a single-crystalline nature. The nickel loading was measured to be $30 \mathrm{wt} \%$ by EDXRF spectroscopy. The final nickel-on-silica geometry showed remarkable thermal stability during high temperature treatment at $973 \mathrm{~K}$ for $10 \mathrm{~h}$, due to the strong Ni-O-Si bonding.

The nickel-on-silica nanoparticles were employed as nanocatalysts for hydrogen transfer of acetophenone. The reactions were carried out with 2-propanol as a hydrogen donor at $353-423 \mathrm{~K}$ in the presence of $\mathrm{NaOH}$. The conversion yield was found to be dependent on the catalyst amount, the temperature, and the reaction time. Entry 2 (Table 4) represents the optimized conditions, where $0.05 \mathrm{~mol} \%$ of the catalyst with respect to the substrate concentration was used at $373 \mathrm{~K}$ for $1 \mathrm{~h}$, and the conversion reached $93 \%$ without any formation of by-products. This activity is the highest reported for heterogeneous nickel catalysts for hydrogen transfer reactions
Table 4 Reduction of acetophenone to 1-phenylethanol by hydrogen transfer catalyzed by nickel-on-silica nanocatalysts

\begin{tabular}{ccccc} 
Entry & $\begin{array}{c}\text { Catalyst } \\
(\mathrm{mol} \%)\end{array}$ & $\mathrm{T}(\mathrm{K})$ & $\mathrm{Time}(\mathrm{h})$ & $\begin{array}{c}\text { Conv. } \\
(\%)^{\mathrm{a}}\end{array}$ \\
\hline 1 & 0.01 & 373 & 1 & 79 \\
2 & 0.05 & 373 & 1 & 93 \\
3 & 0.1 & 423 & 1 & 97 \\
4 & 0.1 & 373 & 1 & 94 \\
5 & 0.1 & 353 & 1 & 54 \\
6 & 0.1 & 373 & 0.5 & 88 \\
\hline
\end{tabular}

${ }^{\mathrm{a}}$ Determined by ${ }^{1} \mathrm{H}-\mathrm{NMR}$ spectroscopy; Yields are based on the amount of acetophenone used. Adapted from Ref. [55]

$[53,54]$, and may result from the small particle size $(\sim 3 \mathrm{~nm})$ and uniform dispersion of the active nanoparticles on the silica spheres. After the reaction, the nickel-on-silica nanocatalysts were readily recovered by centrifugation and could be reused five times without loss of catalytic activity.

The nickel-on-silica nanostructures were obtained via a nickel phyllosilicate intermediate, and since similar phyllosilicate phases exist for metals such as cobalt and magnesium, it should be possible to prepare successful heterogeneous catalysts containing other metal-on-silica structures by the same route.

\section{Summary and outlook}

Rational design of a catalyst can enhance various aspects of a reaction. In this review, we have demonstrated that a metal@silica yolk-shell type nanostructure is an excellent bifunctional catalyst framework. The yolk-shell nanocatalysts have many advantages compared to conventional catalyst structures. Au@SiO 2 yolk-shell catalysts exhibited core size-dependent reaction properties in $p$-nitrophenol reduction, and both the silica layers and the metal cores could be modified enhancing catalytic activity by more than an order of magnitude. $\mathrm{Ni@SiO}$ yolkshell nanocatalysts were prepared on a gram scale, and were employed for steam methane reforming. Because the yolk-shell structure prevented particle sintering, the catalysts showed remarkable high 
temperature stability as well as reusability that were comparable to state-of-the-art commercial catalysts. Reduction of the core size in the $\mathrm{Ni@SiO}$ yolk-shell structure afforded materials with significantly increased activities in heterogeneous hydrogen transfer reactions, due to the small particle size and clean surfaces. Another bifunctional catalyst structure, nickelon-silica spheres, was synthesized by conversion of $\mathrm{Ni} @ \mathrm{SiO}_{2}$ core-shell nanoparticles, and showed high activity and reusability for hydrogen transfer reactions.

We have used the $\mathrm{Au} @ \mathrm{SiO}_{2}$ and $\mathrm{Ni@SiO}$ yolk-shell systems to demonstrate the power of rational catalyst design, but other metal and metal oxide compositions can also be combined together to expand the applicability of bifunctional nanocatalysts. $\mathrm{Co} @ \mathrm{SiO}_{2}$ and $\mathrm{Fe}_{\mathrm{SiO}}$ yolk-shell nanoparticles were prepared by the core etching method [39], and the $\mathrm{Pt} @ \mathrm{SiO}_{2}$ yolk-shell structure was synthesized from a bimetallic core of $\mathrm{NiPt} @ \mathrm{SiO}_{2}$ via selective dissolution of the nickel component [58]. The $\mathrm{Au} @ \mathrm{ZrO}_{2}$ yolk-shell structure has been prepared and used for $\mathrm{CO}$ oxidation reactions by other groups $[19,20]$. The next goal in yolk-shell nanocatalyst research will be the design of bifunctional catalysts optimized for specific reactions with suitable metal and metal oxide compositions and appropriate morphology. For instance, $\mathrm{P} \mathrm{e} @ \mathrm{TiO}_{2}$ should be effective in photocatalytic degradation, whilst $\mathrm{Pd} @ \mathrm{C}$ should be the best catalyst for hydrogenation and $\mathrm{C}-\mathrm{C}$ coupling reactions. Another challenge for catalyst design is to solve the problem of catalyst deactivation. The major causes of the deactivation are particle sintering and coke deposition on the catalyst surface [44]. The former was resolved by the yolk-shell catalyst design, but the latter could not be overcome by a simple approach. Optimizing the metal-metal oxide combination with a specific morphology may provide ways of solving the deactivation problem. Finally, catalyst design has to focus on reaction selectivity as well as activity. Precise control of the surface structure of active nanoparticles and the diffusion rates of reactants through porous silica shells will be helpful in addressing this selectivity issue [59].

In order to advance the design of catalysts with nanoscopic morphologies, many different tools such as theoretical calculations, spectroscopic measurements, synthetic techniques, and reaction tests and simulations have to be simultaneously employed. If this teamwork is realized, the field of "nanocatalysts" will have a big impact in both academia and in industry, and change our life for the better.

\section{Acknowledgements}

This work was supported from the Korea Basic Science Institute (KBSI) grant (No. T29330), and the Korea Science and Engineering Foundation (KOSEF), funded by the Korean Government (MEST) (No. R11-2007050-00000-0).

Open Access: This article is distributed under the terms of the Creative Commons Attribution Noncommercial License which permits any noncommercial use, distribution, and reproduction in any medium, provided the original author(s) and source are credited.

\section{References}

[1] Bell, A. T. The impact of nanoscience on heterogeneous catalysis. Science 2003, 299, 1688-1691.

[2] Boudart, M. Heterogeneous catalysis by metals. J. Mol. Catal. 1985, 30, 27-38.

[3] Rolison, D. R. Catalytic nanoarchitectures - the importance of nothing and the unimportance of periodicity. Science 2003, 299, 1698-1701.

[4] Zhu, J.; Somorjai, G. A. Formation of platinum silicide on a platinum nanoparticle array model catalyst deposited on silica during chemical reaction. Nano Lett. 2001, 1, 8-13.

[5] Haruta, M. Catalysis of gold nanoparticles deposited on metal oxides. CATTECH 2002, 6, 102-115.

[6] Xia, Y.; Halas, N. J. Synthesis and plasmonic properties of nanostructures. Mater. Res. Soc. Bull. 2005, 30, 338-348.

[7] El-Sayed, M. A. Some interesting properties of metals confined in time and nanometer space of different shapes. Acc. Chem. Res. 2001, 34, 257-264.

[8] Kresge, C. T.; Leonowicz, M. E.; Roth, W. J.; Vartuli, J. C.; Beck, J. S. Ordered mesoporous molecular sieves synthesized by a liquid-crystal template mechanism. Nature 1992, 359, $710-712$.

[9] Fukuoka, A.; Higashimoto, N.; Sakamoto, Y.; Inagaki, S.; Fukushima, Y.; Ichikawa, M. Preparation, XAFS characterization, and catalysis of platinum nanowires and nanoparticles in mesoporous silica FSM-16. Top. Catal. 2002, 18. 73-78. 
[10] Yang, C. -M.; Liu, P. H.; Ho, Y. -F.; Chiu, C. -Y.; Chao, K. -J. Highly dispersed metal nanoparticles in functionalized SBA-15. Chem. Mater. 2003, 15, 275-280.

[11] Rioux, R. M.; Song, H.; Hoefelmeyer, J. D.; Yang, P.; Somorjai, G. A. High-surface-area catalyst design: Synthesis, characterization, and reaction studies of platinum nanoparticles in mesoporous SBA-15 silica. J. Phys. Chem. B 2005, 109, 2192-2202.

[12] Song, H.; Rioux, R. M.; Hoefelmeyer, J. D.; Komor, R.; Niesz, K.; Grass, M.; Yang, P.; Somorjai, G. A. Hydrothermal growth of mesoporous SBA-15 silica in the presence of PVP-stabilized Pt nanoparticles: Synthesis, characterization, and catalytic properties. J. Am. Chem. Soc. 2006, 128, 3027-3037.

[13] Yin, Y.; Rioux, R. M.; Erdonmez, C. K.; Hughes, S.; Somorjai, G. A.; Alivisatos, A. P. Formation of hollow nanocrystals through the nanoscale Kirkendall effect. Science 2004, 304, 711-714.

[14] Kim, M.; Sohn, K.; Na, H. B.; Hyeon, T. Synthesis of nanorattles composed of gold nanoparticles encapsulated in mesoporous carbon and polymer shells. Nano Lett. 2002, 2, 1383-1387.

[15] Kamata, K.; Lu, Y.; Xia, Y. Synthesis and characterization of monodispersed core-shell spherical colloids with movable cores. J. Am. Chem. Soc. 2003, 125, 2384-2385.

[16] Kim, J. Y.; Yoon, S. B.; Yu, J. -S. Fabrication of nanocapsules with $\mathrm{Au}$ particles trapped inside carbon and silica nanoporous shells. Chem. Commun. 2003, 790-791.

[17] Zhang, T.; Ge, J.; Hu, Y.; Zhang, Q.; Aloni, S.; Yin. Y. Formation of hollow silica colloids through a spontaneous dissolution-regrowth process. Angew. Chem., Int. Ed. 2008, 47, 5806-5811.

[18] Joo, S. H.; Park, J. Y.; Tsung, C. -K.; Yamada, Y.; Yang, P.; Somorjai, G. A. Thermally stable Pt/mesoporous silica coreshell nanocatalysts for high-temperature reactions. Nat. Mater. 2009, 8, 126-131.

[19] Arnal, P. M.; Comotti, M.; Schüth, F. High-temperaturestable catalysts by hollow sphere encapsulation. Angew. Chem. Int. Ed. 2006, 45, 8224-8227.

[20] Huang, X.; Guo, C.; Zuo, J.; Zheng, N.; Stucky, G. D. An assembly route to inorganic catalytic nanoreactors containing sub-10-nm gold nanoparticles with anti- aggregation properties. Small 2009, 5, 361-365.

[21] Harada, T.; Ikeda, S.; Ng, Y. H.; Sakata, T.; Mori, H.; Torimoto, T.; Matsumura, M. Rhodium nanoparticle encapsulated in a porous carbon shell as an active heterogeneous catalyst for aromatic hydrogenation. $A d v$. Funct. Mater. 2008, 18, 2190-2196.

[22] Giersig, M.; Ung, T.; Liz-Marzán, L. M.; Mulvaney, P.
Direct observation of chemical reactions in silica-coated gold and silver nanoparticles. Adv. Mater. 1997, 9, 570-575.

[23] Zhang, Q.; Wang, W.; Goebl, J.; Yin, Y. Self-templated synthesis of hollow nanostructures. Nano Today 2009, 4, 494-507.

[24] Sun, Y.; Mayers, B.; Xia, Y. Metal nanostructures with hollow interiors. Adv. Mater. 2003, 15, 641-646.

[25] Liu, S.; Han, M. -Y. Silica-coated metal nanoparticles. Chem. Asian J. 2010, 5, 36-45.

[26] Lee, J.; Park, J. C.; Song, H. A nanoreactor framework of a $\mathrm{Au} @ \mathrm{SiO}_{2}$ yolk/shell structure for catalytic reduction of p-nitrophenol. Adv. Mater. 2008, 20, 1523-1528.

[27] Seo, D.; Park, J. C.; Song, H. Polyhedral gold nanocrystals with $O_{\mathrm{h}}$ symmetry: From octahedra to cubes. J. Am. Chem. Soc. 2006, 128, 14863-14870.

[28] Stöber, W.; Fink, A. Controlled growth of monodisperse silica spheres in the micron size range. J. Colloid Interface Sci. 1968, 26, 62-69.

[29] Panigrahi, S.; Basu, S.; Praharaj, S.; Pande, S.; Jana, S.; Pal, A.; Ghosh, S. K.; Pal, T. Synthesis and size-selective catalysis by supported gold nanoparticles: Study on heterogeneous and homogeneous catalytic process. J. Phys. Chem. C 2007, 111, 4596-4605.

[30] Sau, T. K.; Pal, A.; Pal, T. Size regime dependent catalysis by gold nanoparticles for the reduction of eosin. J. Phys. Chem. B 2001, 105, 9266-9272.

[31] Wan, Y.; Zhao, D. On the controllable soft-templating approach to mesoporous silicates. Chem. Rev. 2007, 107, 2821-2860.

[32] Lee, J.; Park, J. C.; Bang, J. U.; Song, H. Precise tuning of porosity and surface functionality in $\mathrm{Au} @ \mathrm{SiO}_{2}$ nanoreactors for high catalytic efficiency. Chem. Mater. 2008, 20, 5839-5844.

[33] Yano, L.; Fukushima, Y. Synthesis of mono-dispersed mesoporous silica spheres with highly ordered hexagonal regularity using conventional alkyltrimethylammonium halide as a surfactant. J. Mater. Chem. 2004, 14, 1579-1584.

[34] Li, T.; Lee, H.; Park, K. Comparative stereochemical analysis of glucose-binding proteins for rational design of glucose-specific agents. J. Biomater. Sci., Polym. Ed. 1998, 9, 327-344.

[35] Love, J. C.; Estroff, L. A.; Kriebel, J. K.; Nuzzo, R. G.; Whitesides, G. M. Self-assembled monolayers of thiolates on metals as a form of nanotechnology. Chem. Rev. 2005, 105, 1103-1169.

[36] Chechik, V.; Crooks, R. M.; Stirling, C. J. M. Reactions and reactivity in self-assembled monolayers. Adv. Mater. 2000, 12, 1161-1171. 
[37] Gershevitz, O.; Sukenik, C. N. In situ FTIR-ATR analysis and titration of carboxylic acid-terminated SAMs. J. Am. Chem. Soc. 2004, 126, 482-483.

[38] Gellman, A. J.; Shukla, N. Nanocatalysis: More than speed. Nat. Mater. 2009, 8, 87-88.

[39] Park, J. C.; Bang, J. U.; Lee, J.; Ko, C. H.; Song, H. $\mathrm{Ni} @ \mathrm{SiO}_{2}$ yolk-shell nanoreactor catalysts: High temperature stability and recyclability. J. Mater. Chem. 2010, 20, 1239-1246.

[40] Liu, C. -M.; Guo, L.; Wang, R. -M.; Deng, Y.; Xu, H. -B.; Yang, S. Magnetic nanochains of metal formed by assembly of small nanoparticles. Chem. Commun. 2004, 2726-2727.

[41] Haryanto, A.; Fernando, S.; Murali, N.; Adhikari, S. Current status of hydrogen production techniques by steam reforming of ethanol: A review. Energy Fuels 2005, 19, 2098-2106.

[42] Hu, C.; Gao, Z.; Yang, X. Fabrication of mesoporous Ni-8YSZ and its catalytic activity for carbon dioxide reforming of methane. Energy Fuels 2007, 21, 2950-2954.

[43] Matsumura, Y.; Nakmori, T. Steam reforming of methane over nickel catalysts at low reaction temperature. Appl. Catal. A. 2004, 258, 107-114.

[44] Sehested, J. Four challenges for nickel steam-reforming catalysts. Catal. Today 2006, 111, 103-110.

[45] Ko, C. H.; Park, J. G.; Park, J. C.; Song, H.; Han, S. -S.; Kim, J. -N. Surface status and size influences of nickel nanoparticles on sulfur compound adsorption. Appl. Surf. Sci. 2007, 253, 5864-5867.

[46] Nguyen, L. Q.; Abella, L. C.; Gallardo, S. M.; Hinode, H. Effect of nickel loading on the activity of $\mathrm{Ni} / \mathrm{ZrO}_{2}$ for methane steam reforming at low temperature. React. Kinet. Catal. Lett. 2008, 93, 227-232.

[47] Valden, M.; Lai, X.; Goodman, D. W. Onset of catalytic activity of gold clusters on titania with the appearance of nonmetallic properties. Science 1998, 281, 1647-1650.

[48] Lopez, N.; Janssens, T. V. W.; Clausen, B. S.; Xu, Y.; Mavrikakis, M.; Bligaard, T.; Nørskov, J. K. On the origin of the catalytic activity of gold nanoparticles for lowtemperature CO oxidation. J. Catal. 2004, 223, 232-235.
[49] Somorjai, G. A. Introduction to Surface Chemistry and Catalysis; Wiley: New York, 1994.

[50] Park, J. C.; Lee, H. J.; Kim, J. Y.; Park, K. H.; Song, H. Catalytic hydrogen transfer of ketones over $\mathrm{Ni} @ \mathrm{SiO}_{2}$ yolk-shell nanocatalysts with tiny metal cores. J. Phys. Chem. C 2010, 114, 6381-6388.

[51] Osso-Asare, K.; Arriagada, F. J. Preparation of $\mathrm{SiO}_{2}$ nanoparticles in a non-ionic reverse micellar system. Colloids Surf. 1990, 50, 321-339.

[52] Park, J.; Kang, E.; Son, S. U.; Park, H. M.; Lee, M. K.; Kim, J.; Kim, K. W.; Noh, H. -J.; Park, J. -H.; Bae, C. J.; Park, J. -G.; Hyeon, T. Monodisperse nanoparticles of $\mathrm{Ni}$ and $\mathrm{NiO}$ : Synthesis, characterization, self-assembled superlattices, and catalytic applications in the Suzuki coupling reaction. Adv. Mater. 2005, 17, 429-434.

[53] Alonso, F.; Riente, P.; Yus, M. Hydrogen-transfer reduction of carbonyl compounds catalyzed by nickel nanoparticles. Tetrahedron Lett. 2008, 49, 1939-1942.

[54] Alonso, F.; Riente, P.; Yus, M. Hydrogen-transfer reduction of carbonyl compounds promoted by nickel nanoparticles. Tetrahedron 2008, 64, 1847-1852.

[55] Park, J. C.; Lee, H. J.; Bang, J. U.; Park, K. H.; Song, H. Chemical transformation and morphology change of nickel-silica hybrid nanostructures via nickel phyllosilicate. Chem. Commun. 2009, 7345-7347.

[56] Guo, Z.; Du, F.; Li, G.; Cui, Z. Controlled synthesis of mesoporous $\mathrm{SiO}_{2} / \mathrm{Ni}_{3} \mathrm{Si}_{2} \mathrm{O}_{5}(\mathrm{OH})_{4}$ core-shell microspheres with tunable chamber structures via a self-template method. Chem. Commun. 2008, 2911-2913.

[57] McDonald, A.; Scott, B.; Villemure, G. Hydrothermal preparation of nanotubular particles of a 1:1 nickel phyllosilicate. Micropor. Mesopor. Mater. 2009, 120, 263-266.

[58] Park, J. C.; Kim, J. Y.; Heo, E.; Park, K. H.; Song, H. Formation of platinum-centered yolk-shell nanostructures by sacrificial nickel spacers. Langmuir 2010, DOI: 10.1021/1a101248g.

[59] Somorjai, G. A.; Kliewer, C. J. Reaction selectivity in heterogeneous catalysis. React. Kinet. Catal. Lett. 2009, 96, 191-208. 